DOI: 10.36910/6775-2524-0560-2020-38-05

УДК: 515.2

Ісмаілова Неллі Петрівна, д. т. н., доцент

https://orcid.org/0000-0003-0181-4420

Елісєєв Ігор Михайлович, здобувач

https://orcid.org/0000-0002-1106-7230

Військова академія (м. Одеса)

\title{
МОДЕЛЮВАННЯ СПРЯЖЕНИХ КІНЕМАТИЧНИХ ПОВЕРХОНЬ ЗА ДОПОМОГОЮ МЕТОДА ГВИНТОВОГО ПЕРЕТВОРЕННЯ В СИСТЕМЕ МАТLАВ
}

Ісмаілова Н. П., Елісєєв І. М. Моделювання спряжених кінематичних поверхонь за допомогою метода гвинтового перетворення в системі MATLAB. Запропоновано комп'ютерне моделювання спряжених поверхонь еліптичний параболоїд і осі - конічна гвинтова лінія в системі MATLAB.

Ключові слова: спряжені кінематичні поверхні, еліптичний параболоїд, конічна гвинтова лінія, система MATLAB.

Исмаилова Н. П., Елисеев И. М. Моделирование сопряженных кинематических поверхностей с помощью метода винтового преобразования в системе MATLAB. Предложено компьютерное моделирование сопряженных поверхностей- эллиптичный параболоид и оси - коническая винтовая линия в системе MATLAB

Ключевые слова; сопряженные кинематические поверхности, эллиптический параболоид, коническая винтовая линия, система MATLAB

N. Ismailova , I. Yelisyeyev. Design of the attended kinematics surfaces by means of method of spiral transformation to the system MATLAB. Computer simulation of mating surfaces is proposed - an elliptical paraboloid and axes - a conical helix in the MATLAB system.

Keywords: mating kinematic surfaces, elliptical paraboloid, conical helix, MATLAB system.

Постановка наукової проблеми. У роботі пропонується геометричне моделювання спряжених кінематичних поверхонь методом гвинтового перетворення, для практичного використання обробки деталей, що мають просторово-складну поверхню тісно пов'язану з утворенням взаємно-огинаючих спряжених поверхонь. [1]. Комп'ютерне геометричне моделювання складних спряжених кінематичних поверхонь підвищує продуктивність розрахунково-конструкторських робіт.

Аналіз досліджень. Комп’ютерне моделювання спряжених поверхонь деталей в машинобудуванні складної форми вирішує проблему підвищення точності профілювання та

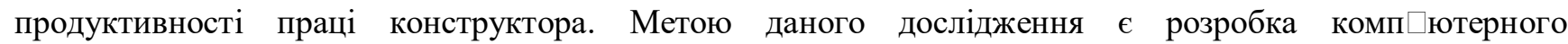
моделювання за допомогою метода гвинтового перетворення в системі MATLAB, спряжених поверхонь деталей в машинобудуванні.

Основна частина. У методі гвинтового перетворення окрім кута повороту задається шаг зрушення. При реалізації методу кругового перетворення шукана поверхня $\Sigma$, була отримана за допомогою ліній рівнів, що не дозволяє виконувати над ними ніяких дій, окрім повороту. Таким чином (Теорема 1), спочатку виконується переміщення початкової поверхні $\Phi$ на заданий шаг $\mathrm{h}$, а потім виконується кругове перетворення отриманої внаслідок переміщення поверхні $\Phi^{*}$. При виконання послідовності дій, криволінійна вісь також має бути переміщена на шаг h.

\section{Теорема 1.}

Поверхня Готримана узагальненим гвинтовим перетворенням поверхні Ф відносно кривої т (и) з функціями $\varphi(\sigma, \tau)$ и $h(\sigma, \tau)$. Тоді існує така поверхня Ф, яка при узагальненому круговому перетворенні навколо тісї же кривої т (u) з тією же функцією $h(\sigma, \tau)$ формує поверхню $\Sigma$.

Розглянемо реалізацію методу гвинтового перетворення, грунтованого на методі кругового перетворення [4], стосовно поверхні - еліптичний параболоїд, заданий параметричним рівнянням (1) i осі - конічна гвинтова лінія, задана параметричним рівнянням (2). 


$$
\begin{gathered}
\left\{\begin{array}{l}
x=a \cdot u \cdot \cos v \\
y=b \cdot u \cdot \sin v, \\
z=0.5 \cdot u^{2}
\end{array}\right. \\
\text { где } 0 \leq u \leq 5,0 \leq v \leq \pi, a=3, b=2 \\
\left\{\begin{array}{c}
x=x_{0}+t \cdot \sin t \\
y=y_{0}+t \cdot \cos t \\
z=z_{0}+c \cdot t
\end{array}\right. \\
\text { где } c=\frac{H}{2 \cdot \pi}, 0 \leq t \leq 2 \pi, H=5, x_{0}=5, y_{0}=-25, z_{0}=-2
\end{gathered}
$$

Значення шага гвинтового перетворення $\mathrm{h}=10$, кут повороту $\varphi=45^{\circ}$. 3 урахуванням шага гвинтового перетворення переміщений еліптичний параболоїд заданий параметричним рівнянням (3), а переміщена конічна гвинтова лінія параметричним рівнянням (4).

$$
\begin{gathered}
\left\{\begin{array}{l}
x=a \cdot u \cdot \cos v \\
y=b \cdot u \cdot \sin v, \\
z=h+0.5 \cdot u^{2}
\end{array}\right. \\
\text { где } 0 \leq u \leq 5,0 \leq v \leq \pi, a=3, b=2 \\
\qquad \begin{array}{l}
x=x_{0}+t \cdot \sin t \\
y=y_{0}+t \cdot \cos t, \\
z=h+z_{0}+c \cdot t
\end{array} \\
\text { где } c=\frac{H}{2 \cdot \pi}, 0 \leq t \leq 2 \pi, H=5, x_{0}=5, y_{0}=-25, z_{0}=-2
\end{gathered}
$$

Змінивши синтаксис побудови кругового перетворення, приведений нижче, отримаємо результат, показаний на рис.1-4.

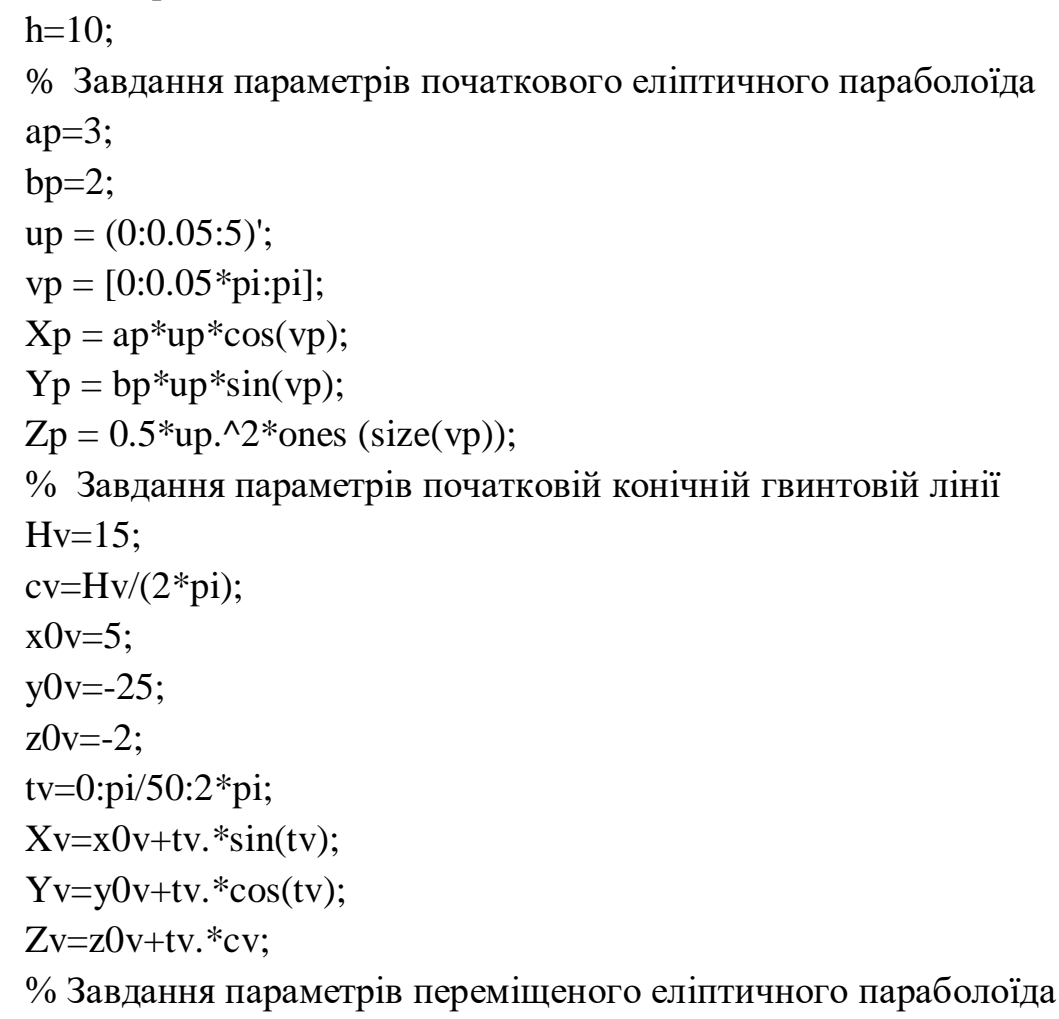


$\mathrm{Xph}=\mathrm{ap} * \mathrm{up} * \cos (\mathrm{vp})$

Yph $=$ bp*up*sin(vp);

$\mathrm{Zph}=\mathrm{h}+0.5^{*}$ up. $^{\wedge} 2 *$ ones (size(vp));

$\%$ Завдання параметрів переміщеній конічній гвинтовій лінії

$\mathrm{Xvh}=\mathrm{x} 0 \mathrm{v}+\mathrm{tv} . * \sin (\mathrm{tv})$

$\mathrm{Yvh}=\mathrm{y} 0 \mathrm{v}+\mathrm{tv} \cdot * \cos (\mathrm{tv})$;

$\mathrm{Zvh}=\mathrm{h}+\mathrm{z} 0 \mathrm{v}+\mathrm{tv} .{ }^{*} \mathrm{cv}$;

\% Висновок на екран початкових і переміщених еліптичного параболоїда і конічної гвинтової лінії в цьому ж вікні

Figure ('Color','w')

ElPar=mesh $(\mathrm{Xp}, \mathrm{Yp}, \mathrm{Zp})$;

xlabel('x'); ylabel('y'); zlabel('z')

hold on

KonVin=plot3(Xv,Yv,Zv);

grid on

hold on

ElParh=mesh(Xph,Yph,Zph);

hold on

KonVinh=plot3(Xvh,Yvh,Zvh);

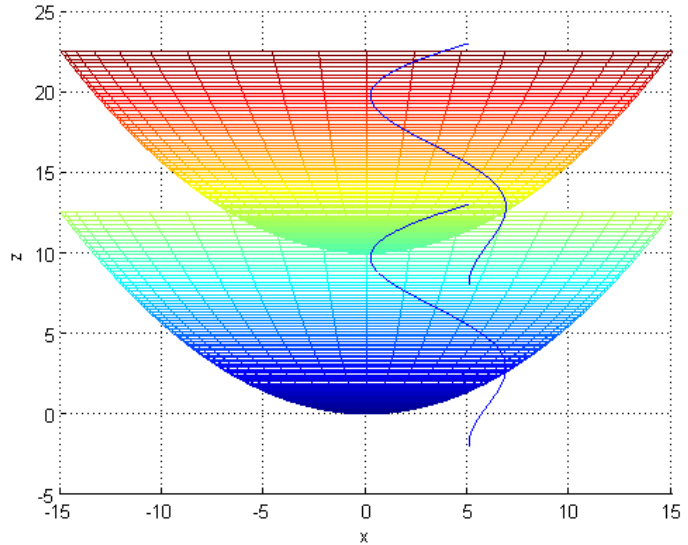

Рис.1. Проекція на площину XZ

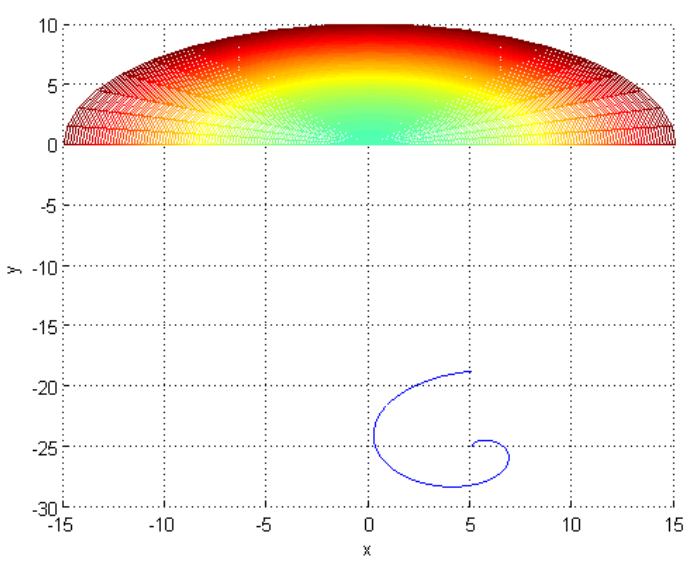

Рис.3. Проекція на площину XY

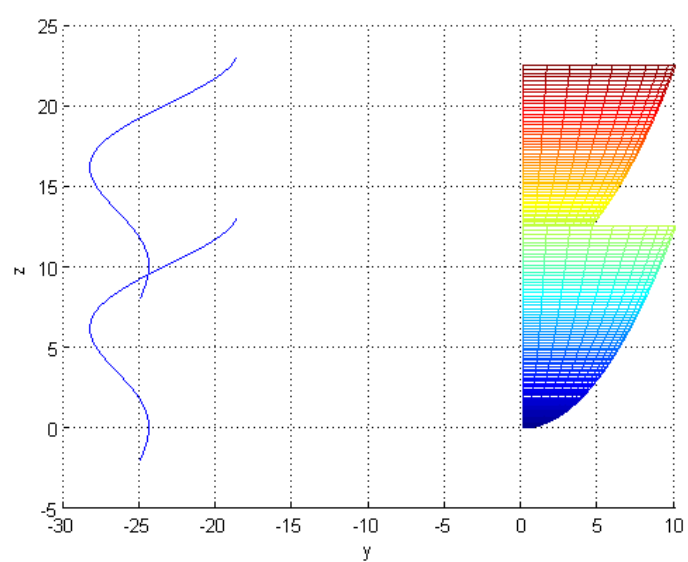

Рис.2. Проекція на площину $\mathrm{YZ}$

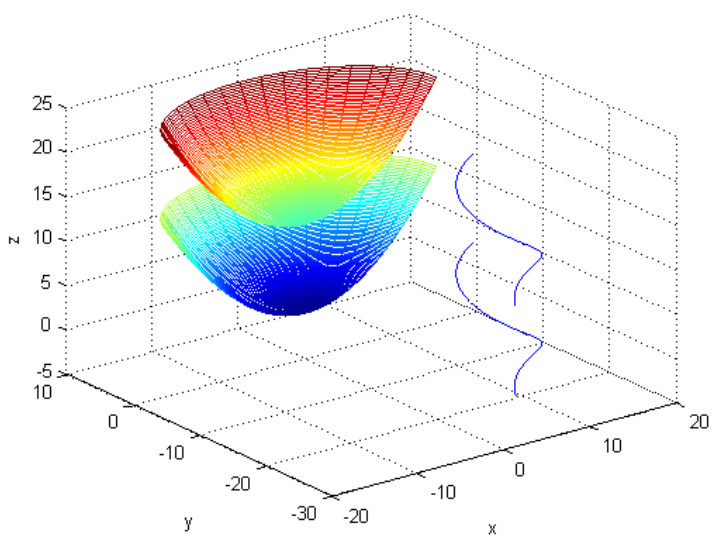

Рис.4. Тривимірне представлення

Визначимо максимальне і мінімальне значення z для переміщеної криволінійної поверхні 
$\operatorname{miPh}=\min (\mathrm{Zph})$;

$\min Z \mathrm{ph}=\operatorname{miPh}(1)$;

$\operatorname{maPh}=\max (\mathrm{Zph})$;

$\operatorname{maxZ} \mathrm{ph}=\operatorname{maPh}(1)$;

Побудовані лінії рівня для криволінійної поверхні.

[ur] $=[\operatorname{minZph}: 0.1: \operatorname{maxZph}]$;

hold on

[contEP, hEP]=contour3(Xph, Yph, Zph, ur);

Визначена довжина масиву ur.

lenUr=length(ur);

Визначимо точки перетину переміщеної конічної гвинтової лінії з горизонтальними площинами, відповідним рівням [ur]. Для цього підставимо в параметричне рівняння (2) значення $\mathrm{z}=[\mathrm{ur}]$ i вичислимо значення хрр і урр.

$$
\begin{aligned}
& {[\mathrm{t} 0]=([\mathrm{ur}]-\mathrm{z} 0 \mathrm{v}-\mathrm{h}) / \mathrm{cv} ;} \\
& \mathrm{xpp}=\mathrm{x} 0 \mathrm{v}+\sin (\mathrm{t} 0) . * \mathrm{t} 0 ; \\
& \mathrm{ypp}=\mathrm{y} 0 \mathrm{v}+\cos (\mathrm{t} 0) . * \mathrm{t} 0 ;
\end{aligned}
$$

Повернемо кожну лінію рівня на кут $45^{\circ}$ навколо відповідної точки перетину криволінійної осі відносно осі Z. Для цього скористаємося функцією Rotate Different Center (lines, xC, yC, zC, length, angle), створеною при розробці методу кругового перетворення, де lines - набір ліній рівня, хC, уC, zC координати точок перетину криволінійної осі 3 горизонтальною площиною рівня, length - довжина масиву, angle - кут повороту.

function Rotate Different Center( lines, $\mathrm{xC}, \mathrm{yC}, \mathrm{zC}$, length, angle )

for $\mathrm{i}=1$ :length

end

rotate(lines(i), [l $\left.\begin{array}{lll}0 & 1\end{array}\right]$, angle, [xC(i) yC(i) zC(i)])

end

У вікні Command Window викликана функція повороту.

Rotate Different Center (hEP,xpp,ypp,ur,lenUr,45)

Результат перетворення (Рис.5-10).

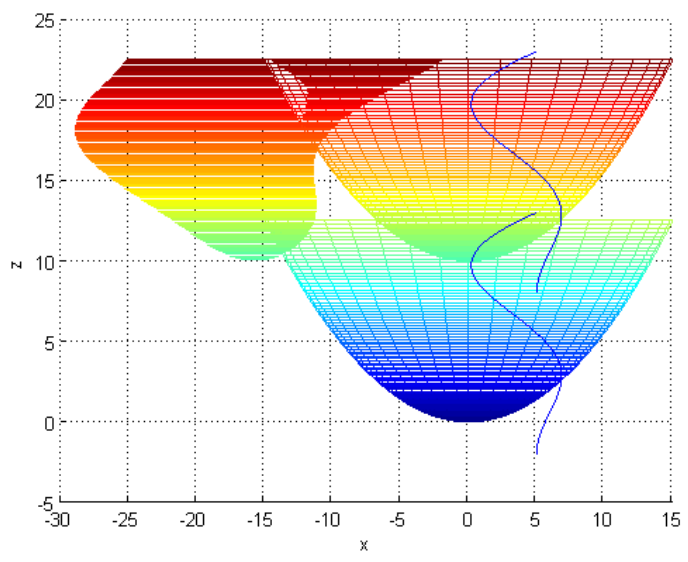

Рис.5. Проекція на площину XZ

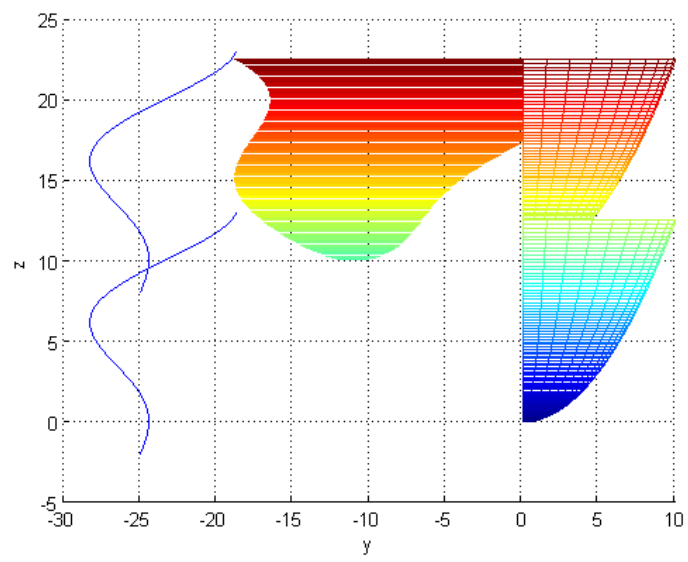

Рис.6. Проекція на площину YZ 


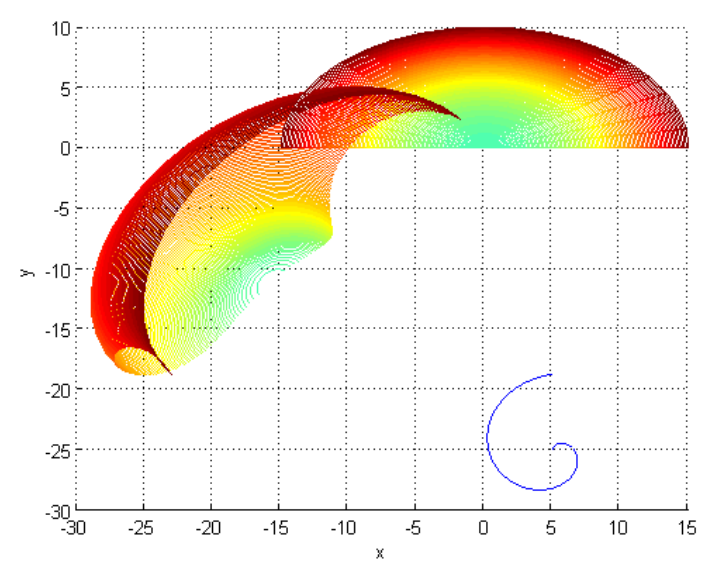

Рис.7. Проекція на площину XY

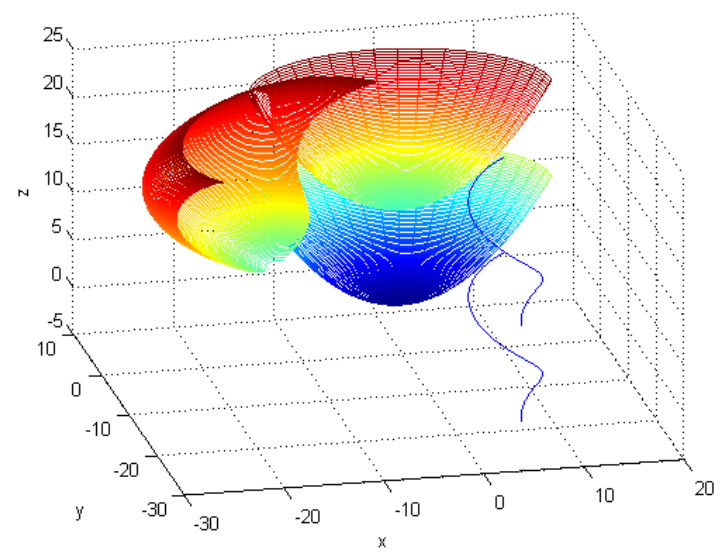

Рис.9. Тривимірне представлення

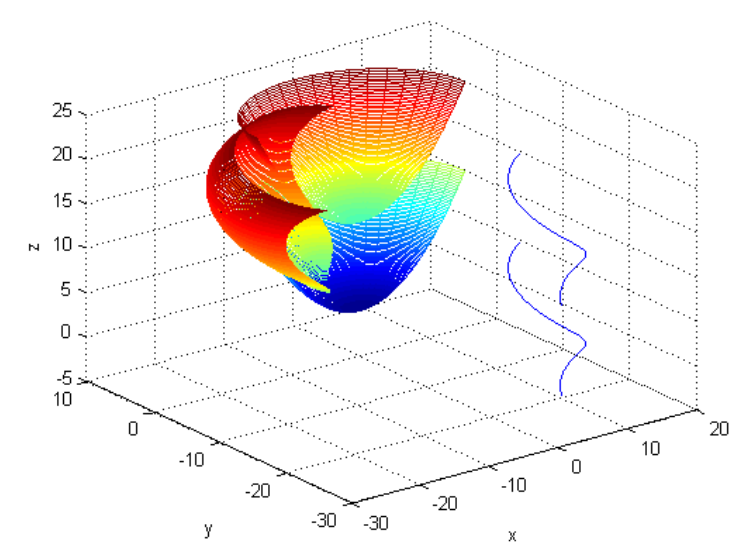

Рис.8. Тривимірне представлення

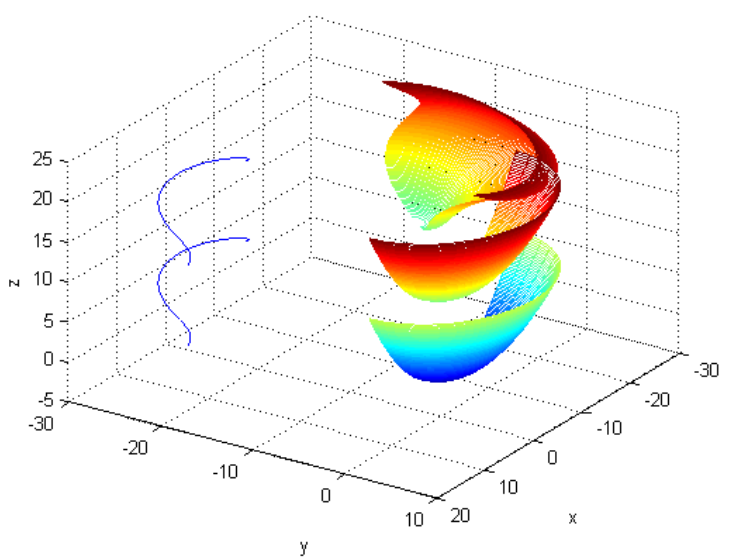

Рис.10. Тривимірне представлення

Для наочного представлення початкових даних і отриманого результату створимо новий графік (Рис.11-16).

\%Відображення початкових даних і результату.

Figure ('Color','w')

$\mathrm{ElPar}=\mathrm{mesh}(\mathrm{Xp}, \mathrm{Yp}, \mathrm{Zp})$;

xlabel ('x'); ylabel('y'); zlabel('z')

hold on

KonVin=plot3 $(\mathrm{Xv}, \mathrm{Yv}, \mathrm{Zv})$;

hold on

[contEP, hEP]=contour3(Xph, Yph, Zph, ur);

Rotate Different Center (hEP,xpp,ypp,ur,lenUr,45) 


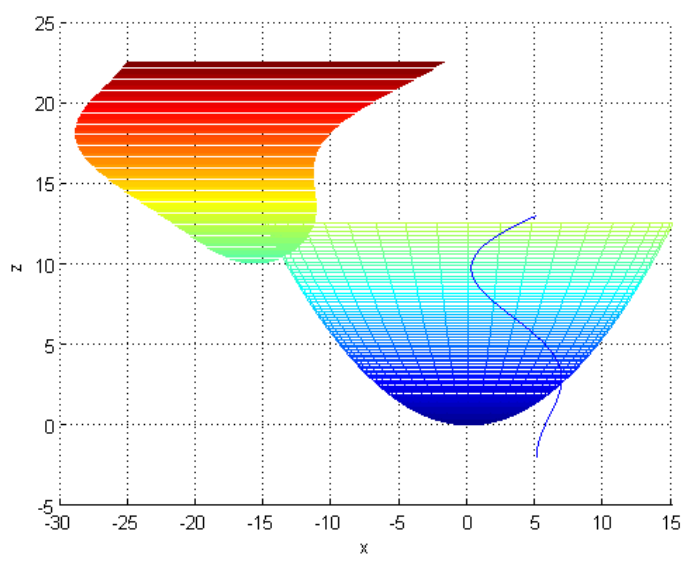

Рис.11. Проекція на площину XZ

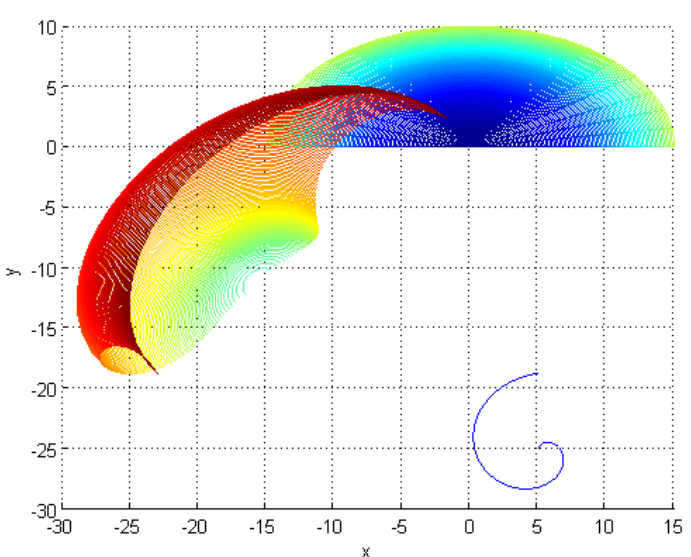

Рис.13. Проекція на площину XY

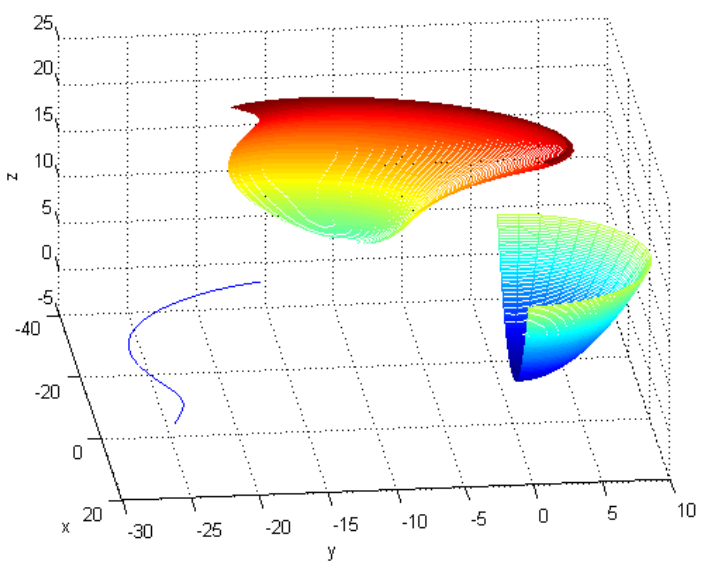

Рис.15. Тривимірне представлення

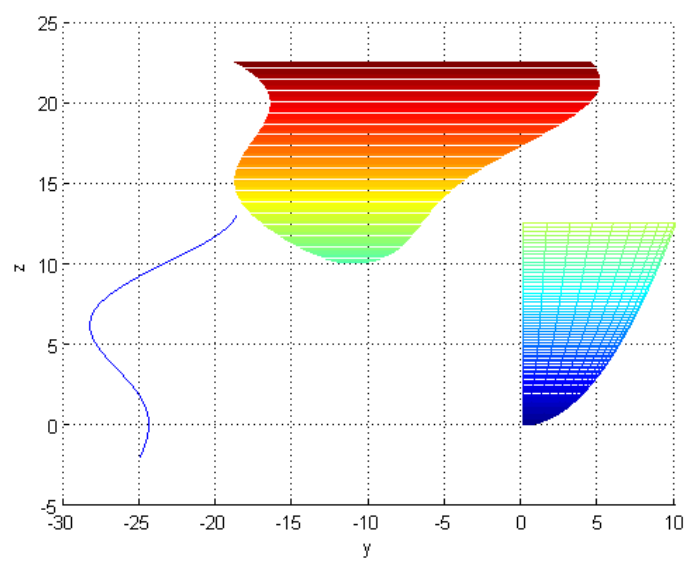

Рис.12. Проекція на площину YZ

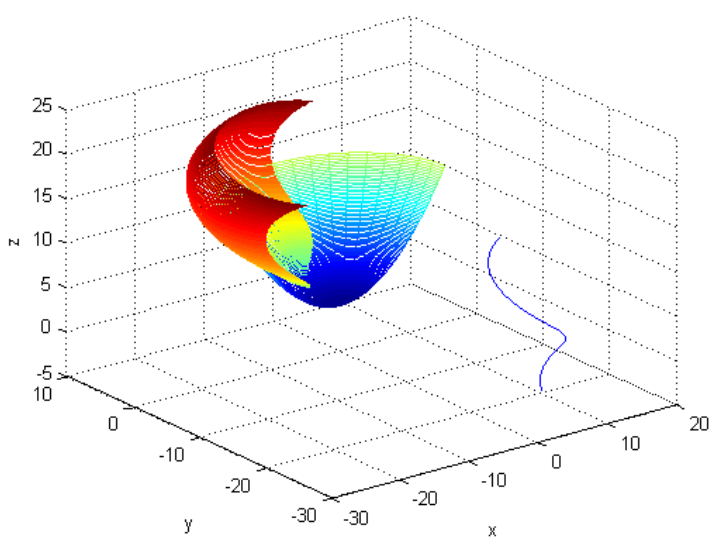

Рис.14. Тривимірне представлення

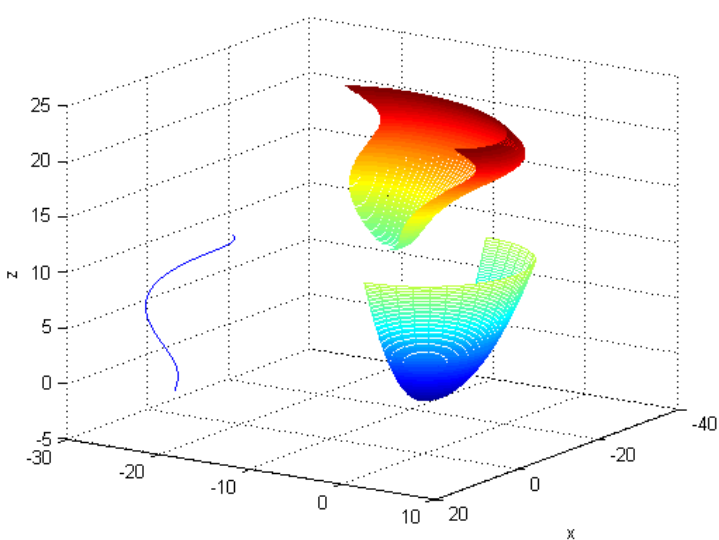

Рис.16. Тривимірне представлення

Рисунки 5-10 служать для наочної демонстрації методу гвинтового перетворення, а, отже, немає необхідності відображати ї надалі. Таким чином, синтаксис методу гвинтового перетворення, не включає відображення допоміжних криволінійній поверхні і криволінійній осі.

У цей час, практично всі проектні рішення виконуються за допомогою САПР. Це дозволяє істотно скоротити час на проектування. Але не завжди за допомогою стандартних засобів комп'ютерного моделювання можна вирішити поставлене завдання. У зв'язку із цим виникає необхідність у створенні 
спеціальних підпрограм для побудови методів проектування спряжених поверхонь, тому що в них $\epsilon$ криволінійна вісь, напрямна, і утворююча.

Розроблений геометричний метода гвинтового перетворення за допомогою комп'ютерного моделювання дозволяє вирішить складні завдання конструювання спряжених поверхонь, підвищити точність i продуктивність інженерної праці i створювати конкурентно-здатні вироби в машинобудуванні, літакобудуванні, кораблебудуванні.

Висновки та перспективи подальшого дослідження. У результаті проведених досліджень ми розробили підпрограму для визначення кругового і гвинтового перетворення спряжених поверхонь до рішення проблеми конструкторських робіт в машинобудуванні яка має можливість підвищення точності профілювання та продуктивності. Подальші дослідження які розроблені у напрямі розробки кругового та гвинтового перетворення спряжених поверхонь є узагальнений метод, який наблизиться до вирішення проблеми виключення інтерференції при профілювання деталей в машинобудуванні.

\section{Список бібліографічного опису.}

1. Подкоритов А.Н., Исмаилова Н.П., Дюкре Л.Г. Метод формирования сопряженных винтовых нелинейчатых поверхностей семейством огибающих геликоидов. Геометричне та комп'ютерне моделювання. - Вип..17. - ХДУХТ. - Харків, 2007. - С.12-15.

2. Ісмаілова Н. П. Твердотільне моделювання спряжених поверхонь на базі параметричного кінематичного гвинта [Текст] /Ісмаілова Н. П. Комп'ютерно-інтегровані технології: освіта, наука, виробництво. - Луцьк, 2015. - С. 69-74.

3. Ісмаілова Н.П., Трушков Г.В. Геометричне моделювання просторового параметричного кінематичного гвинта/ Комп'ютерно-інтегровані технології: освіта, наука, виробництво. Луцький національний технічний університет. Науковий журнал. №30-31 2018. Луцк - 2018. С. 187-195

4. Ісмаілова Н.П., Єлісєєв І.П. Моделювання спряжених кінематичних поверхонь за допомогою метода гвинтового перетворення в системе MATLAB /Комп’ютерно-інтегровані технології: освіта, наука, виробництво. Луцький національний технічний університет. Науковий журнал. №37 2019. Луцк - 2019. С. 66-71.

\section{References}

1. Podkoritov AN, Ismailova NP, Ducret LG Method of forming conjugate helical nonlinear surfaces by a family of envelope helicoids. Geometric and computer modeling. - Issue 17. - CDHD. - Kharkiv, 2007. - P.12-15.

2. Ismailova NP Solid state modeling of conjugate surfaces based on parametric kinematic screw [Text] / Ismailova NP Computer-integrated technologies: education, science, production. Lutsk, 2015, pp. 69-74.

3. Ismailova NP, Trushkov GV Geometric modeling of spatial parametric kinematic screw /Computer-integrated technologies: education, science, production. Lutsk National Technical University.Scientific journal. №30-31 2018. Lutsk 2018. P. 187-195

4. Ismailova NP, I. Yelisyeyev, Model of conjugated kinematic surfaces on top of the helical rebuild method in the MATLAB system/ Computer-integrated technologies: education, science, production. Lutsk National Technical University.Scientific journal. №37 2019. Lutsk - 2019. P. 66-71. 